\title{
Comparison Between 2-Dimensional and 3-Dimensional Echocardiographic Scoring in Predicting Success of Percutaneous Transvenous Mitral Commissurotomy
}

MOHAMMAD FAISAL IBN KABIR, MANZOOR MAHMOOD, CHAUDHURY MESHKATAHMED, JAHANARAARZU, FAKHRUL ISLAM KHALED, MUHAMMED MOBAROK HOSSAIN, MOHAMMAD ABDUR RAHMAN

Department of Cardiology, Bangabandhu Sheikh Mujib Medical University (BSMMU), Dhaka,

Address of Correspondence: Dr Mohammad Faisal Ibn Kabir, Department of Cardiology, Bangabandhu Sheikh Mujib Medical University, Dhaka. E mail:mfi_kabir@yahoo.com

\begin{abstract}
:
Like many other developing countries rheumatic heart disease still poses a great threat to the health system of this country due to its devastating outcome in inappropriately treated cases. PTMC remains a prime treatment option in suitable cases of rheumatic mitral stenosis. But there are controversies and discrepancies in the conventional 2-D echo assessment for proper selection of patients for PTMC. With the advent of newer technologies like 3-D echo with newer options, better assessments are naturally expected. This 3-D echo system raised the hope to fill the shortcomings of 2-D Wilkins' score. To facilitate this 3-D echo with its scoring system it has to be testified against an established, widely accepted and well-understood existing scoring system that has its limitations. Thus it creates a fertile ground whereupon many studies are being done as it is chosen here. In this study, considering all ethical issues, data were collected from 50 mitral stenosis patients who were scored by means of 2-D Wilkins' and RT3DE scoring systems prior to PTMC and reassessed echocardiographically to define post PTMC outcome and then from this result to compare the two scoring systems as predictors of outcome of PTMC. This study showed a clear female preponderance (78\%) of mitral stenosis patients most of whom belonged to the age group 31-40 years. According to Wilkins' score all are in the 'mild' or 'moderate' group but RT3DE scored $24 \%$ as severe. Both the 2-D mild and moderate groups had good number of suboptimal outcomes (34\% and $24 \%$ respectively) although the moderate group had comparatively more optimal outcomes (76\% in comparison to 66\%) than the mild group (although the difference is not statistically significant), that is, the 2-D score is less consistent. On the other hand the RT3DE score showed a gradual fall of optimal outcome in an ascending order of the score from mild to severe and the differences in outcomes among different groups was statistically significant. This showed a clear superiority of the 3-D scoring system over the 2- D in terms of accuracy and consistency. In the 3-D 'severe' group percentage of suboptimal outcome was very high(91.7\%). This is the group of patients that were not correctly detected by 2-D echo and as a result the outcome assessment was far from accurate. Due to the higher accuracy and consistency 3-D echo is likely to be more reproducible than the 2-D, 3-D echocardiography was more accurate and consistent than 2-D echocardiography in assessing outcome of PTMC. So, the RT3DE scoring system can be a good supplement to the existing 2-D scoring system.
\end{abstract}

Introduction:

Acute rheumatic fever (ARF) \& rheumatic heart disease (RHD) have long been considered as an important cause of cardiac related morbidity all over the world, especially in developing countries. But its prevalence has fallen during the last two decades. Still it is considered immensely important due to its notorious effect on the heart and its potentially preventable character.

Rheumatic heart disease (RHD) causes a significant number of morbidity and mortality in Bangladesh and accounts for $34 \%$ - $42 \%$ of hospital admission of all cardiac cases. The prevalence of rheumatic fever and RHD in Bangladesh is 1.2 and 1.3 per thousand population respectively ${ }^{7}$.

Echocardiography has evolved as the most predominant diagnostic imaging technique in Cardiology. Over the last 5 decades the diagnostic capability of echocardiography has increased dramatically from M-mode to two-dimensional (2D) imaging. Recent advances in ultrasound instrumentation and computer technology have led to three-dimensional (3D) echocardiography, thus introducing a new era in cardiovascular imaging ${ }^{9}$. 
Every imaging technique in Cardiology aims at a complete visualization and comprehensive assessment of cardiac morphology and pathology as the heart is a complex geometric structure. Therefore, analysis of the heart in motion in all three or four (including time) dimensions can further facilitate and enhance the diagnostic capabilities of echocardiography. The 3-dimensional echocardiography is still in its evolution and at the phase of early adaptation with respect to its clinical application. It should complement current echocardiographic techniques by providing better understanding of the topographical aspects of pathology and refined definition of the spatial relationships of (intra) cardiac structures. Furthermore, it provides new indices not described previously by 2dimensional echocardiography and makes the existing ones more accurate. The assessment of patients with mitral valve disease is one of the most challenging as well as promising clinical applications of 3-dimensional echocardiography ${ }^{17}$.

Two-dimensional echocardiography plays a key role in selecting the most appropriate therapeutic strategy in patients with mitral stenosis ${ }^{17}$. Apart from estimation of the transmitral pressure gradient, two-dimensional echocardiography can calculate mitral valve area by planimetry and pressure half-time (Robiolio et al 1998). Also, two-dimensional echocardiography is essential in the selection of patients for percutaneous mitral valvuloplasty (PMV) ${ }^{26}$. Among all available mitral valve scoring systems, Wilkins's score is the most commonly used $^{18}$. This score evaluate mitral valve thickness, mobility, leaflet calcification, and the degree of subvalvular apparatus thickening and shortening / changes $^{19}$. A favourable Wilkins's score(<8points) is highly predictive of a good outcome after PTMC ${ }^{18}$. More recently it has been shown that other factors, such as commissural fusion and calcification, are also strong predictors of outcomes after PTMC ${ }^{28}$.

The introduction of real-time three-dimensional echocardiography and advances in analysis software have improved mitral orientation and evaluation. Several studies have reported improved accuracy and superiority of realtime three-dimensional echocardiography over twodimensional echocardiography for mitral valve area estimation ${ }^{8,12,25}$. Real-time three-dimensional echocardiography allows a unique "en face" view and morphologic analysis of the entire mitral valve apparatus, including the mitral valve annulus, the subvalvular apparatus, and its anatomic relation to other nearby structures. In the current study it is aimed to assess a new real-time three-dimensional echocardiography score for the assessment of the mitral valve in patients with mitral stenosis in comparison with Wilkins's score for the prediction of PTMC outcomes.

\section{Methods:}

This cross-sectional analytical study was conducted in the University Cardiac centre, BSMMU from December 2012 to May, 2014. A total of 50 patients were enrolled in the study. Detailed history, clinical examination and relevant investigation reports of all patients were recorded in pre-designed data collection sheet at the beginning of the study. Patients who were suspected or diagnosed as a case of chronic rheumatic heart disease in the form of mitral stenosis and were already enrolled for transthoracic Doppler echocardiography in BSMMU (both in patients and out patients) for further evaluation were selected to include in the study. Among these patients who had proven mitral stenosis by means of 2-D echo with suitable morphology for PTMC and consented for doing PTMC and taking part in the study were selected as a case. At first 2-D Wilkins' score was done. RT3DE score was done in the same setting. After PTMC outcome was assessed by means of 2-D and 3D echo on the basis of MVA, MR grade and commissural splitting. After collection of data they were edited and summarized and then analyzed and interpreted. Data were processed and analyzed by using computer software SPSS 16 (Statistical package for social sciences version 16). Categorical data was expressed in percentage or number. Parametric data was expressed in mean + SD. Categorical data was evaluated by Chi square and Fisher's Exact test. Significance was defined as p value $<0.05$. Kappa statistic was calculated as a measure of agreement between 2D and 3D echocardiography.

\section{Results:}

Amongst 50 patients included in our study, there were no deaths or any complications, with the exception of worsening MR that was associated with PTMC. Among 50 patients that took part in the study 26(52\%) were in the $31-40$ year age group, $19(38 \%)$ in the 20 -30 year age group and $5(10 \%)$ in the $>40$ year age group. 39 (78\%) patients were female. So this study showed a preponderance of mitral stenosis in 31-40 year aged females (Table-I). The mean height, weight and BMI of the patients of this study were $154.80 \pm 7.18 \mathrm{~cm}, 48.60 \pm 6.21 \mathrm{~kg}$ and $20.35 \pm 1.01 \mathrm{~kg} / \mathrm{m}^{2}$ respectively. 
Table-I

Distribution of study patients by age and sex $(n=50)$

\begin{tabular}{lcc}
\hline Characteristics & Frequency & Percentage (\%) \\
\hline Age in years & 19 & 38 \\
$20-30$ & 26 & 52 \\
$31-40$ & 5 & 10 \\
$>40$ & $32.80 \pm 7.58$ & \\
Mean \pm SD & & \\
Sex & 11 & 22 \\
Male & 39 & 78 \\
Female & & \\
\hline
\end{tabular}

$\mathrm{n}=$ number of study patients

Out of 50 patients 2-D Wilkins'score categorized 29 patients(58\%) in 'mild' group and 21 patients (42\%) in 'moderate' group. But according to 3-D score 10 patients (20\%) were in the 'mild', 28(56\%) were in the 'moderate', and 12 (24\%) were in the 'severe' group. So, there is characteristic and statistically significant $(\mathrm{P}<0.05)$ difference between 2-D and 3-D scoring system in categorizing MS patients (Table-II).

\section{Table-II}

Distribution of study patients by their severity of 2D (Wilkins's score) and $3 D$ (RT3DE score) echocardiographic score $(n=50)$

\begin{tabular}{lccccc}
\hline Score & \multicolumn{2}{c}{ Wilkins's score } & \multicolumn{2}{c}{ RT3DE score } & P value \\
& $\mathrm{n}$ & $\%$ & $\mathrm{n}$ & $\%$ & \\
\hline Mild & 29 & 58.0 & 10 & 20.0 & $0.027^{\mathrm{s}}$ \\
Moderate & 21 & 42.0 & 28 & 56.0 & \\
Severe & 0 & 00 & 12 & 24.0 & \\
\hline
\end{tabular}

Statistical analysis was done by Fisher's exact test $\mathrm{n}=$ number of study patients

$\mathrm{s}=$ significant

Post PTMC echocardiography showed there were partial commissural splitting in 11 patients (22\%) and complete commissural splitting in 39 patients (78\%) (Table-III).

\section{Table-III}

Distribution of patients by the degree of post PTMC commissural opening/ splitting $(n=50)$

\begin{tabular}{lcc}
\hline & Frequency & Percentage (\%) \\
\hline Partial & 11 & 22.0 \\
Complete & 39 & 78.0 \\
\hline
\end{tabular}

$\mathrm{n}=$ number of study patients

Prior to PTMC no patient in this study had more than mild MR and mostly had no MR. Post PTMC echocardiography showed that in 5 patients(10\%) there were no or trivial
MR, and in 30(60\%) patients had mild, 10(20\%) patients had moderate, and 5(10\%) had severe MR (Table-IV).

\section{Table-IV}

Distribution of patients by the post PTMC Grade of $M R(n=50)$

\begin{tabular}{lcc}
\hline MR Grade & Frequency & Percentage (\%) \\
\hline Trivial (or absent) & 5 & 10.0 \\
Mild & 30 & 60.0 \\
Moderate & 10 & 20.0 \\
Severe & 5 & 10.0 \\
\hline
\end{tabular}

$\mathrm{n}=$ number of study patients

Outcome is assessed post procedure on the basis of achieved mitral valve area, MR grade and commissural splitting. Taking into account these three parameters total 35 patients (70\%) had optimal outcome and 15 patients (30\%) had suboptimal outcome (Table-V).

Table-V

Distribution of patients by outcome $(n=50)$ : optimal or suboptimal

\begin{tabular}{lcc}
\hline Outcome & Frequency & Percentage (\%) \\
\hline Optimal & 35 & 70 \\
Suboptimal & 15 & 30 \\
\hline
\end{tabular}

$\mathrm{n}=$ number of study patients

19 patients out of 29 mild patients (according to 2-D Wilkins' score) and 16 patients out of 21 moderate patients had optimal outcome. That is, 66\% of the 'mild group' patients had optimal and 34\% had sub-optimal outcome. And, 76\% of the 'moderate group' patients had optimal and $24 \%$ had sub-optimal outcome. So, percentage wise 'moderate group' patients had relatively better outcome than the 'mild group'. But the difference in outcome in different groups is not statistically significant $(\mathrm{P}>0.05)$ (Table VI).

\section{Table-VI}

Comparison of Wilkins's score and outcome

\begin{tabular}{|c|c|c|c|c|c|c|}
\hline \multirow{3}{*}{$\begin{array}{l}\text { Wilkins's } \\
\text { score }\end{array}$} & \multirow{3}{*}{ Frequency } & \multicolumn{4}{|c|}{ Outcome } & \multirow[t]{3}{*}{$\mathrm{P}$ value } \\
\hline & & \multicolumn{2}{|c|}{$\begin{array}{c}\text { Optimal } \\
(\mathrm{n}=35)\end{array}$} & \multicolumn{2}{|c|}{$\begin{array}{l}\text { Suboptimal } \\
\quad(n=15)\end{array}$} & \\
\hline & & $\mathrm{No}$ & $\%$ & $\overline{\mathrm{No}}$ & $\overline{\%}$ & \\
\hline Mild & 29 & 19 & $54.3(66)$ & 10 & $66.7(34)$ & $0.416^{\mathrm{ns}}$ \\
\hline Moderate & 21 & 16 & $45.7(76)$ & 5 & $33.3(24)$ & \\
\hline Severe & 0 & 0 & 00 & 0 & 00 & \\
\hline Total & 50 & 35 & 100 & 15 & 100 & \\
\hline
\end{tabular}

Statistical analysis was done by Chi-square test $\mathrm{n}=$ number of study patients

ns $=$ not significant 
All 10 patients of 'mild group' (according to RT3DE score), 24 patients out of 28 'moderate group' patients and 1 patient out of 10 'severe group' had optimal outcome. That is, $100 \%$ of the 'mild group' patients, $86 \%$ of the 'moderate group' patients and $8.3 \%$ of the 'severe group' had optimal outcome. So, percentage wise there was a gradual fall of success rate from mild to severe group. Again, the difference in outcome in different groups was statistically significant $(\mathrm{P}<0.05)$ (Table VII).

\section{Table-VII}

Comparison of RT3DE score and outcome

\begin{tabular}{|c|c|c|c|c|c|c|}
\hline \multirow{3}{*}{$\begin{array}{l}\text { RT3DE } \\
\text { score }\end{array}$} & \multirow[t]{3}{*}{ Frequency } & \multicolumn{4}{|c|}{ Outcome } & \multirow[t]{3}{*}{$\mathrm{P}$ value } \\
\hline & & \multicolumn{2}{|c|}{$\begin{array}{c}\text { Optimal } \\
(\mathrm{n}=35)\end{array}$} & \multicolumn{2}{|c|}{$\begin{array}{l}\text { Suboptimal } \\
(\mathrm{n}=15)\end{array}$} & \\
\hline & & No & $\%$ & $\mathrm{No}$ & $\%$ & \\
\hline Mild & 10 & 10 & $28.6(100)$ & 0 & 0 & $0.001^{\mathrm{s}}$ \\
\hline Moderate & 28 & 24 & 68.6(86) & 4 & $26.7(14)$ & \\
\hline Severe & 12 & 1 & $2.8(8.3)$ & 11 & 73.3(91.7) & \\
\hline Total & 50 & 35 & 100 & 15 & 100 & \\
\hline
\end{tabular}

Statistical analysis was done by Fisher's Exact test $\mathrm{n}=$ number of study patients

$\mathrm{s}=$ significant

The strength of agreement between 2-D and 3-D echo are found to be 'poor' (ê-0.04) and so the difference between 2-D and 3-D scoring system in categorizing MS patients was statistically significant $(\mathrm{P}<0.05)$ (Table VIII \& II).

\section{Table-VIII}

Assessment of agreement between 2-DE and 3-DE

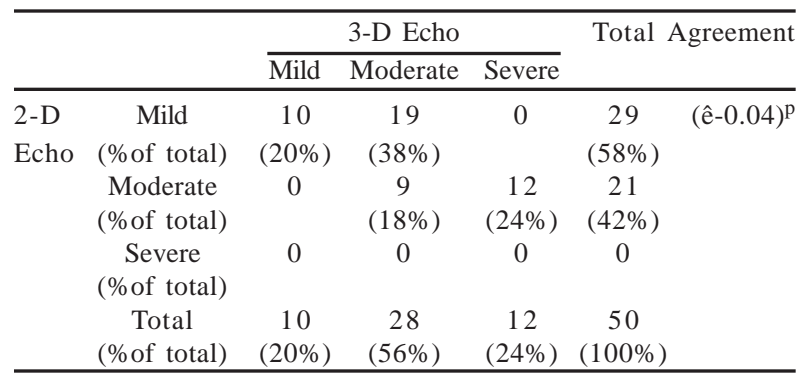

$\mathrm{p}=$ poor agreement

$\mathrm{p}=$ poor agreement

\section{Discussion:}

PTMC is considered the main stay of treatment in patients with $\mathrm{MS}^{4,13,14}$. It is time tested, safe and effective treatment 4,6,26 and although challenging, still, technically feasible in a relatively resource poor set up. But, despite the careful selection of patients using Wilkins's score, PTMC carries a considerable failure rate ${ }^{10,15}$. This led us to search for other predictors of successful PTMC like a new 3-D score that might add valuable elements to the existing assessment tools. Wilkins' score, as well as RT3DE score, concentrated on mitral valve apparatus and did not consider patient demographics, technical and echocardiographic features including other systems like pulmonary artery hypertension. In this respect both these scoring systems are far from comprehensive. But in this study only mitral valve apparatus was focused in pre-PTMC echocardiographic assessment of outcome. As a result, in true sense comparison of these two scoring systems are a comparison between the part of a whole.

One of the most significant developments of the last decade in echocardiographic imaging of the heart was the evolution of 3-dimensional (3D) imaging from slow and labor-intense offline reconstruction to real-time volumetric imaging. This imaging modality provides valuable clinical information that empowers echocardiographers with new levels of confidence in the diagnosis of heart disease ${ }^{11,14}$ previously described the technological milestones in the development of real-time 3D echocardiographic (RT3DE) imaging and its major advantages over conventional 2-dimensional echocardiography (2DE) and reviewed the published literature that supported the use of this new methodology in clinical practice. Since 2006, the growing availability of RT3DE technology, its ease of use, and its multiple attractive features have sparked significant interest in the research community, resulting in a large number of publications, most of which have endorsed RT3DE imaging for clinical use by demonstrating its unique capabilities in different scenarios. In parallel, the clinical acceptance of this new tool has broadened significantly. The most recent clinically significant addition is matrixarray transoesophageal echocardiography (TEE), which provides images of unprecedented quality that aid surgeons and interventional cardiologists in planning and guiding procedures and evaluating their outcomes ${ }^{14}$.

The purpose of the present study was to determine and compare the 2D \& 3D echocardiographic assessment of MV apparatus in patients with rheumatic MS and thereby predict the outcome after PTMC.

This study included 50 patients, $78 \%$ of them were female. This fact of female predominance is similar to what was mentioned in some studies from south Asia, the Middle East and North Africa ${ }^{21}$. Girls and women, in particular, seem to be severely affected possibly as a result of being housebound and having to live in overcrowded conditions ${ }^{16}$. The majority of patients belonged to the age group 31-40 years. This can be explained by the fact that the first attack of rheumatic fever usually occurs at the age of 20 to 30 years $2,5,20$. 
.Amongst 50 patients included in this study, there were neither any death nor any major complication, excepting worsening of MR associated with PTMC. An optimal PTMC result was obtained in 35 (70\%) patients opposed to 15 (30\%) who had suboptimal results. Amongst all patients, $5(10 \%)$ patients developed no to trivial MR(10\%), 30 (60\%) patients mild MR and 15 patients (30\%) moderate to severe MR. It may be argued that the overall success rate of the PTMC procedures was $70 \%$ in this study. Sadeghian et al. (2012) reported that amongst 196 patients included in a study, there were no deaths or any complications other than worsening of MR that was associated with PTMC. A successful PTMC result was obtained in 139 (70.9\%) patients as opposed to 57 (29.1\%) who had unsuccessful results that were due to suboptimal secondary MVA $<1.5 \mathrm{~cm}^{2}$ in 50 (25.5\%) patients and postprocedure MR grade $>2$ in 7 (3.6\%). Amongst all patients, the MR severity worsened in 53 (28.2\%) patients by one grade in 34 (18.6\%), two grades in 12 (6.4\%), three grades in $3(1.6 \%)$, and four grades in $3(1.6 \%)$ patients while it remained the same in 108 (57.4) or decreased by one grade in $27(14.4 \%)$ patients after PTMC. Severe MR occurred in 4 (2.0\%) patients following PTMC. Although our study results are not synonymous with it, but more or less the results are compatible to each other.

Using 3-D echocardiography in future studies may provide more accurate parameters for the prediction of the PTMC result since this method provides a unique en face view and morphologic analysis of the entire mitral valve apparatus $^{3}$ and it is superior for the evaluation of leaflet mobility and commissures ${ }^{24}$. The echocardiographic examination aids clinicians to predict overall PTMC success. Successful PTMC results are influenced by patients' age, LA size, and mitral valve thickness.

Again analyzing the study result it is evident that Wilkins' score, although validated for quite some time for prePTMC assessment, is not a hundred percent perfect tool. So, useful addition can be made to it. It is shown in this study that it failed to pin point those cases as 'severe' that were 'severe' according to RT3DE score and group wise these patients had mostly suboptimal outcome. Another key point that should provide food for thought was the better outcome rate amongst the 'moderate' group rather than the 'mild' group. Although small sample size could be the reason for this inconsistency, still, it is too characteristic a point to ignore. By analysis of the data of current study it is found that there was 'poor' agreement between 2-D and 3-D echo and the difference is statistically significant. That is why, if $3-\mathrm{D}$ echo is added as a routine assessment tool with the conventional 2-D echo it would bring a new dimension that is likely to be more accurate and as a result will benefit the patients, the prime goal of any treatment, as also will exhaust the valuable and scanty resources more efficiently and amicably.

\section{Conclusion:}

3-D echocardiography was more accurate and consistent than 2-D echocardiography in assessing outcome of PTMC. But in this study outcome of PTMC was assessed immediately after the procedure; so it is not prudent to comment straight way that this prediction is also wellsuited for long term outcome assessment. Moreover, the small sample size could be the cause of some inconsistencies of the 2-D echo findings and can also overestimate or underestimate the benefits of 3-D echo as an assessment tool. In this regard further studies can be done to establish a workable 3-D score for routine clinical use. Again, there is provision to do further studies on 3-D scoring incorporating some other demographic, echocardiographic and technique related parameters. Dreams that inflict desire in the right use of resources and pursuation in cherishing and nurturing expertise could bring about the right changes that take the dormant 'wishes and desires' in the core of a scientific mind to a new height. We live in the realm of science, but we dream of a 'fiction' that will once be 'the scientific fact' so there is no end in the walk of 'science' towards glory; this study is only a step, no doubt, there are many more to come in this particular field of applied medicine.

\section{References:}

1. ACC/AHA. 'Practice guidelines for the management of patients with valvular heart disease: executive summary', $J$ Am Coll Cardiol, 2006; 48: 598-675.

2. Ahmed, J, Mostafa Zaman, M, Monzur Hassan, MM. ‘ Prevalence of rheumatic fever and rheumatic heart disease in rural Bangladesh', Trop Doct., 2005; 35: 160 -161.

3. Anwar, AM, Attia, WM, Nosir, YFM, Soliman, O, Mosad, MA, Othman, M , 'Validation of a new score for the assessment of mitral stenosis using real-time three-dimensional echocardiography', Journal of American Society Echocardiography, 2010; 23: 13-22.

4. Babic, UU, Grujicic, S, Popovic, Z, Djurisisc, Z, Pejcic, P, Vucinic, M. 'Percutaneous transarterial balloon dilatation of the mitral valve: five year experience', Br Heart J, 1992; 67: 185-189.

5. Bradbury, A, Grubb, NR, Newby, BE 2014, 'Cardiovascular diseases’ In: Walker, BR, Colledge, NR, Ralston, SH, Penman, ID (eds.), Davidson's principles and practice of medicine, $22^{\text {nd }}$ edn, Elsevier, Philadelphia, pp. 613-616.

6. Chen, CR, Cheng, TO, Chen, JY, Zhou, YL, Mei, J, Ma, TZ. ‘ Long-term results of percutaneous mitral valvuloplasty with the Inoue balloon catheter', Am J Cardiol , 1992; 70: 1445-1448. 
7. Jasimuddin, A, Zaman, MM, Monzur, HMM. 'Prevalence of rheumatic fever and rheumatic heart disease in rural Bangladesh,' Tropical Doctor, 2005; 35: 160-161.

8. Karp, K, Teien, D, Bjerle, P, Eriksson, P. 'Reassessment of valve area determinations in mitral stenosis by the pressure half-time method: impact of left ventricular stiffness and peak diastolic pressure difference,' Journal of American College of Cardiology, 1989; 1: 594-9.

9. Lange, A, Palka, P, Burstow, DJ, Godman, MJ. 'Threedimensional echocardiography: Historical development and current applications', Journal of American Society Echocardiography, 2001; 14: 12.

10. Leon, MN, Harrell, LC, Simosa, HF, Mahdi, NA, Pathan, AZ, Lopez-Cuellar, J. 'Comparison of immediate and long-term results of mitral balloon valvotomy with the double- balloon versus Inoue techniques,' Am J Cardiol, 1999; 83: 1356-63.

11. Mor-Avi, V, Sugeng, L, Lang, LM. 'Contemporary Reviews in Cardiovascular Medicine,' Circulation, 2009; 119: 314-329.

12. Nakatani, S, Masuyama, T, Kodama, K, Kitabatake, A, Fujii, K, Kamada, T. ' Value and limitations of Doppler echocardiography in the quantification of stenotic mitral valve area: comparison of the pressure half-time and the continuity equation methods,' Circulation , 1988; 77: 78-85.

13. Nobuyoshi, M, Hamasaki, N, Kimura, T, Nosaka, H, Yokoi, $\mathrm{H}$, Yasumoto, $\mathrm{H}$. 'Indications, complications and short-term clinical outcome of percutaneous transvenous mitral commissurotomy,' Circulation, 1989; 80: 782-92.

14. Palacios, I, Block, PC, Brandi, S, Blanco, P, Casal, H, Pulido, JI. 'Percutaneous balloon valvotomy for patients with severe mitral stenosis,' Circulation, 2007; vol. 75: 778-84.

15. Palacios, IF, Sanchez, PL, Harrell, LC, Weyman, AE, Block, PC. 'Which patients benefit from percutaneous mitral balloon valvuloplasty? Prevalvuloplasty and postvalvuloplsty variables that predict longterm outcome,' Circulation, 2002; 105: 1465-71.

16. Radmavati, S. 'Rheumatic heart disease: prevalence and preventive measures in India subcontinent,' Heart, 2001; 86: 127.

17. Rahimtoola, SH, Durairaj, A, Mehra, A, Nuno, I. 'Current evaluation and management of patients with mitral stenosis,' Circulation, 2002; 106: 1183-8.

18. Reid, CL, Chandraratna, PA, Kwanishi, DT, Kotlewski, A, Rahimtoola, SH. 'Influence of mitral valve morphology on double-balloon catheter balloon valvuloplasty in patients with mitral stenosis. Analysis of factors predicting immediate and 3-monthresults,' Circulation, 1989; 80: 515-24.

19. Reid ,CL, Otto, CM, Davis, KB, McKay, CR. 'Influence of the mitral valve morphology on mitral balloon commissurotomy: immediate and six-month results from the NHLBI Balloon Valvuloplasty Registry,' American Heart Journal 1992; 124: 657-65.

20. Riaz, BK, Selim, S, Karim, MN, Chowdhury, KN, Chowdhury, SH, Rahman, MR. 'Risk Factors of Rheumatic Heart Disease in Bangladesh: A Case-Control Study', J Health Popul Nutr., 2013; 31(1): 70-77.

21. Rizvi S, F, Khan, M A, Kundi, A. 'Status of rheumatic heart disease in rural Pakistan', Heart , 2004; 90: 394-399.

22. Robiolio ,PA, Rigolin, VH, Harrison, JK, Kisslo, KB, Bashore, TM. 'Doppler pressure half-time method of assessing mitral valve area: aortic insufficiency does not adversely affect validity,' American Heart Journal , 1998; 136: 718-23.

23. Sadeghian, H, Salarifar, M, Rezvanfard, M, Nematipour, E, Lot_Tokaldany M, Sar Mardanloo, A, Poorhosseini, MR, Semnani, V. 'Percutaneous Transvenous Mitral Commissurotomy: Signi_cance of Echocardiographic Assessment in Prediction of Immediate Result', Arch Iran Med, 2012; 15(10): 629 - 634 .

24. Salustri, A, Becker, AE, van Herwerden, L, Vietter, WB, Ten Cate, F, Roelandt, JR. 'Three-dimensional echocardiography of normal and pathological mitral valve: a comparison with two-dimensional transesophageal echocardiography,' Journal of American College of Cardiology, 1996; 27: 1502-1510.

25. Sugeng, L, Weinert, L, Lammertin, G, Thomas, P, Spencer, KT, Decara, JM. 'Accuracy of mitral valve area measurements using transthoracic rapid freehand 3-dimensional scanning; comparison with non-invasive and invasive methods,' Journal of American Society of Echocardiography, 2003: 16: 1292-300.

26. Vahanian, A, Michel, PL, Cormier, B, Vitoux, B, Michel, X, Slama, M. 'Results of percutaneous mitral commissurotomy in 200 patients,' American Journal of Cardiology, 1998; 63: 847-52.

27. Vijayvergiya, R 2008,' Rheumatic fever and rheumatic heart disease', Elsevier.

28. Wilkins, GT, Weyman, AE, Abascal ,VM, Block, PC, Palcious, IF 1988, 'Percutaneous ballon dilatation of the mitral valve: an analysis of echocardiographic variables related to outcome and the mechanism of dilation,' British Heart Journal, vol. 60, pp. 299-308. 